Document downloaded from:

http://hdl.handle.net/10251/43290

This paper must be cited as:

Ballesteros Pérez, P.; González-Cruz, MC.; Cañavate Grimal, A.; Pellicer, E. (2013). Detecting Abnormal and Collusive Bids in Capped Tendering. Automation in Construction. 31:215-229. doi:10.1016/j.autcon.2012.11.036.

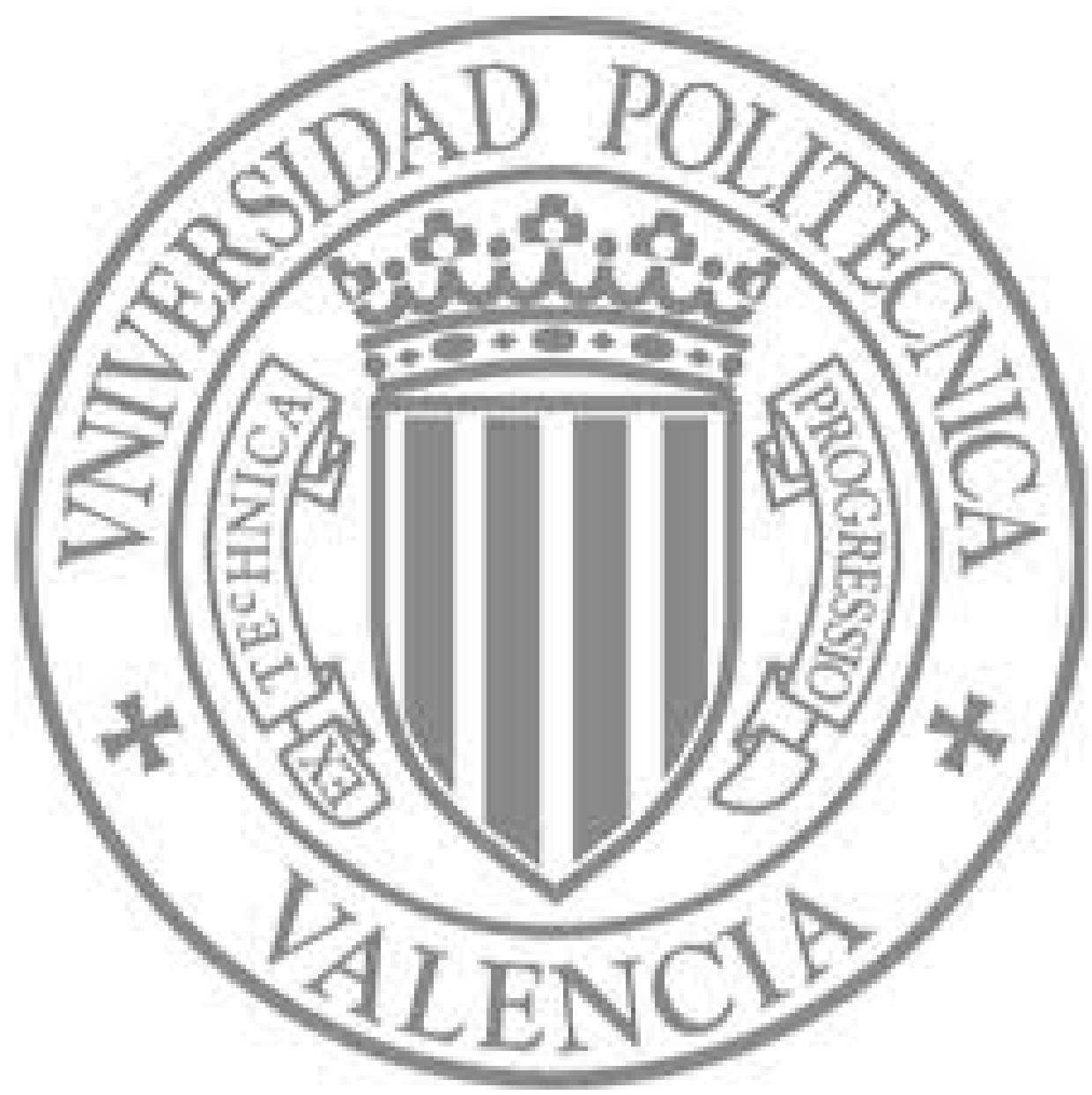

The final publication is available at

http://dx.doi.org/10.1016/j.autcon.2012.11.036

Copyright Elsevier 


\title{
Detecting Abnormal and Collusive Bids in Capped Tendering
}

\author{
Pablo Ballesteros-Pérez \\ Mª Carmen González-Cruz \\ Antonio Cañavate-Grimal \\ Eugenio Pellicer
}

\begin{abstract}
Recent developments in the area of Bid Tender Forecasting have enabled bidders to implement new types of easy-to-use tools for increasing their chances of winning contracts. Although these new tools (such as iso-Score Curve Graphs, Scoring Probability Graphs, and Position Probability Graphs) are designed for bidders in capped tendering (tenders with an upper price limit), some of their principles can also be applied by a Contracting Authority to detect which bidders do not follow a standard pattern, that is, their bids are extremely high or low. Since a collusive bid generally needs to be sufficiently high or low to make an impact on the bid distribution, any person in charge of supervising capped tenders can be alerted to any bidder that might be involved in a cartel after identifying the same abnormal behavior in a series of tenders through simple calculations and a new type of graph.
\end{abstract}

Keywords: tender; auction; collusion; abnormal bid; phony bid; bid-covering.

\section{Introduction}

Collusive tendering (or bid rigging) occurs when businesses that would otherwise be expected to compete, secretly conspire to raise prices or lower the quality of goods or services for purchasers in a bidding process [1]. Collusive tendering can be particularly harmful if it affects public procurement, since in OECD countries public procurement accounts for approximately 15\% of GDP [2] and in other countries that figure is even higher [3].

Such conspiracies take resources from purchasers and taxpayers, diminish public confidence in the competitive process, and undermine the benefits of a competitive marketplace [4]. State and federal legislation have proscribed such agreements to 
protect consumers from collusive behavior, and considerable resources are dedicated every year to prosecuting colluders $[5,6]$.

'Cover bidding' or 'bid-covering' (also called complementary, courtesy, token, or symbolic cover) is the most frequent way in which collusive schemes are implemented [7]. Cover bidding occurs when individuals or firms agree to submit bids that involve at least one of the following: (1) a competitor agrees to submit a bid that is higher than the bid of the designated winner; (2) a competitor submits a bid that is known to be too high to be accepted; or (3) a competitor submits a bid that contains special terms that are known to be unacceptable to the purchaser [2].

Cover bidding is generally designed to give the appearance of genuine competition. Thus, classifying bids as abnormally high or low and fighting collusion is a primary concern for auctioneers or any Contracting Authority since bidders who manage to forma cartel (a group of firms intending to limit competition among the participants in one or several tenders) can harm seriously the Contracting Authority's revenue [8, 9]. In fact, Klemperer [10] and Anderson et al. [11] argue that collusion and other competition policy issues are more relevant for practical auction design than the riskaversion, affiliation, and budget-constraint issues that play a prominent role in mainstream auction theory.

The literature suggests several ways for auctioneers to implement auction rules that discourage collusion $[12,13,14,15,16,17,18]$. However, these theoretical solutions have several practical limitations since collusion-proof mechanisms require the auctioneer to know the distribution functions from which bidders draw their values and know which bidders belong to which cartel.

In practice, such information is difficult, if not impossible, to acquire [9]. It should be noted that collusion schemes can be very difficult to detect as they are typically negotiated in secret and may not be evident from the results of a single tender [5]. Often a collusive scheme is revealed only when one examines a regular pattern of suspicious behavior from a number of tenders over a period of time [1].

Another well-known collusive scheme is so-called 'bid rotation' [19, 20]. In this kind of scheme (not exclusively used with a bid-covering strategy), conspiring firms continue to bid, but agree to take turns being the winning (i.e., lowest qualifying) bidder. The way in which bid-rotation agreements are implemented can vary greatly.

Nevertheless, a correlation between the current result in a particular tender and past results is not necessarily due to collusion. Particularly, when bidders' cost functions exhibit decreasing returns to scale, bid rotation can also result from a competitive 
bidding behavior. That is, for example, firms with idle capacity have lower marginal costs and hence, are more likely to win a contract than those with ongoing contracts $[20,21]$.

To prosecute and, by so doing, deter future collusion, we need to know how to detect collusive behavior. We need a set of tools that can help indicate when certain behavior is collusive or, at least abnormal, in order to point auctioneers or Contracting Authorities in the right direction [22]. While collusive behavior exists in all types of markets, this paper focuses on alerting the possibility of collusive bid-covering by firms competing in either public or private sealed-bid auctions or tenders with other criteria apart from the economic price.

Broadly speaking, sealed-bid auctions and tenders assume that firms submit sealed bids (either only economic bids or technical and economic bids, respectively) for a procurement contract and that the contract is awarded to the lowest (or the economically most advantageous) bidder. These rules are common practice in the vast majority of public sector procurements, and they are used in many auctions in the private sector as well $[5,23]$.

Because of the multiple technical and financial criteria involved in public and private tendering $[24,25,26,27,28,29,30,31,32]$, there is still a need for the development of new tools to help decision makers and improve the selection process for bidders [33].

In this connection, new developments in the area of Bid Tender Forecasting have enabled bidders to implement new kinds of easy-to-use tools for increasing their chances of winning contracts $[34,35,36]$. Although these new tools are genuinely designed for bidders in capped tendering (tenders with an upper limit on price), some of their principles can also be applied by a Contracting Authority to detect which bidders do not follow a regular pattern, that is, their bids are extremely high or low.

This paper presents a new test for detecting abnormally high or low bids among those who enter a tender, and taking advantage of the data, any tender analyst or person in charge of supervising capped tenders will be able to suspect which bidders are involved in a cartel after identifying the same abnormal behavior in a series of tenders by means of a simple method.

\section{Background}

A large body of economic theory has demonstrated that both competitive and collusive bidding strategies depend on the rules of the auction and the cost structure of the bidders $[20,37,38,39,40]$. 
Theories of collusion in auctions also highlight the role of a pre-auction meeting of bidders. Generally, incentives are provided from the winner to the losers. McAfee and McMillan [41] characterized efficient collusion when no side transfer is possible. It is a static scheme in which the choice of the designated winner is independent of the history. The analysis is extended to a repeated framework by Aoyagi [42] and Skrzypacz and Hopenhayn [43], who analyze collusion without side transfer in repeated auctions. In contrast to McAfee and McMillan's static bid rotation [41], they construct dynamic bid rotation schemes in which bid coordination is based on past history.

In contrast to the theoretical literature, the inner working of the bidding rings has attracted little attention in the empirical literature [6, 41], although there is much empirical work aimed at detecting collusion in procurement auctions [44, 45]. Most studies illustrate how the bidding behavior of a set of collusive bidders differs from competitive behavior.

In this connection, Porter and Zona [20] modeled the probability of a bidder winning under competitive bidding. They specify a bidder's bidding function to be linear in observable cost factors, thus imposing an assumption that their coefficients are the same among firms, and then analyze the probability of each bidder's win given the cost factors as a conditional logit model [40].

Subsequently, Bajari and Ye $[46,47]$ thoroughly observed the violation of two conditions: 'conditional independence' and 'exchangeability' that a competitive bidding strategy must always satisfy. The first condition implied by competitive bidding requires that the bids of various competing firms should not be correlated, after we have adjusted for the impact on their bids of all publicly observed information about the project. On the other hand, if a subset of firms (the cartel members) in an industry have coordinated on how to bid before an auction, their bids will typically be correlated in a manner that can be detected.

The second condition implied in competitive bidding is 'exchangeability'. This means that all competing firms behave in the same way when faced with the same cost structure for themselves and rival firms. If the publicly observed factors affecting costs or other information that firms use to compute their bids are permuted or exchanged among firms, then the bids should permute among the firms in the same way when exchangeability holds.

Thus, Bajari and Ye [46, 47] extended the important analysis of Porter and Zona [20, $40]$ in several ways. Firstly, Porter and Zona did not specify an equilibrium model of 
either competitive or collusive bidding in their analysis. Secondly, Bajari and Ye [46, 47] introduced new tests for collusion that were not presented by Porter and Zona that enable a Contracting Authority to address the problem of identifying which bidders are members of the cartel. The tests in Porter and Zona [20,40], on the other hand, took the identity of the cartel members as given.

Finally, Ballesteros-Pérez et al. [34, 35, 36] developed a Bid Tender Forecasting Model (BTFM) applicable to capped tendering. This model capitalizes on a new conception of analyzing bidder behavior and presents its results via three kinds of graphs: iso-Score Curve Graphs, Scoring Probability Graphs, and Position Probability Graphs.

With the aim of identifying those bidders who do not follow a regular or predictable pattern, that is, bidders whose behavior is not 'conditionally independent' and 'exchangeable', the BTFM developed by Ballesteros-Pérez et al. will be partially used and reformulated for detecting extremely high or low phony bids.

\section{Basic definitions}

Spanish tendering terminology is mainly used as this study was carried out in Spain, although some new terms are included. The analysis described in this paper has been applied to capped tenders, that is, tenders with upper price limit stated in the tender specifications by the Contracting Authority.

For the sake of clarity, some terms have been defined (see Appendix A).

'Bidder's Drop' $\left(D_{i}\right)$ is the discount or bid reduction on the initial price of a contract $(A)$ submitted by a given contractor $i$ for a particular capped tender. It is mathematically expressed as:

$$
D_{i}=1-\frac{B_{i}}{A}
$$

where $D_{i}$ is the drop (expressed in per-unit values) of bidder ' $i$ '; $B_{i}$ is the bid (expressed in monetary values) of bidder 'i'; and $A$ is the initial Amount of money (in monetary value) of the tender (generally set by the Contracting Authority in many countries).

In Spanish tendering practice, when referring to bid amounts, it is usual to use a discount on the contract value A. This discount is called 'baja' in Spanish, meaning literally 'fall' or 'drop'. This term has been translated as 'drop' because no similar concept has been found in the international literature.

For the comparison of bids in different bidding processes with different initial bid amounts $(A)$ for each tender, it is preferable to use Drops $\left(D_{i}\right)$ rather than monetarybased Bids $\left(B_{i}\right)$. 
'Economic Scoring Formula' (ESF) refers to the mathematical expressions used to assign numerical scores to each bidder from the bid price expressed in drops. ESF comprises the mathematical operations that provide the score (which is not important for this study) and the mathematical expression that determines which bids are 'abnormal' or 'risky' (Abnormally Low Bids Criteria, ALBC), i.e. too high or too low.

So far, ALBC has received much less attention in the literature than the analysis of bidding behaviors [48], the exception being the work on outliers (another term for 'abnormal bids') in Bid Tender Forecasting Models developed by Skitmore [31, 49, 50].

Generally, the final aim of the ALBC is to reject 'abnormally low bidders'; that is, those who bid below a minimum price threshold, which is usually pre-set deterministically on the tender specifications by a Contracting Authority. After being identified by the ALBC, the 'abnormal bidders' should provide evidence about the consistency of their proposals (both technically and economically). The problem is that no deterministic ALBC is able to predict which price implies a zero profit, since that depends largely on each bidder and each particular project. As a consequence, ALBC usually end up conditioning the final bidders' bids distribution instead of accurately discriminating 'abnormal' from 'normal' bidders.

The method proposed in this paper can be considered an alternative non-deterministic ALBC that adapts to the final distribution of bidders, being able to distinguish bidders who have made bids based on similar technical and economic criteria from those who have not, and hence, might be considered as 'abnormal'.

\section{Analysis of bidders' bids distribution}

The proposed method is designed to detect abnormally high or low bids, while alerting for a possible collusion phenomenon. The method requires a previous analysis to determine the probable positions that each competitor will occupy, i.e., to study the bid distances from each other, so that the various competitor positions can be compared to a standard pattern distribution.

It is also necessary to limit the number of potential bidders that would probably bid in a future tender. An extensive literature has focused on the study of the potential number of bidders [51,52]. However, when a tender is overdue, the number of bidders is known and this variable enables setting a pattern distribution that must be close enough to the distribution generated by the bidders. 
From here on, some of the principles in the Position Probability Graphs devised by Ballesteros-Pérez et al. [36] will be applied, which demonstrate that the $\mathrm{N}$ bidders are usually placed equidistantly on average at the same probability intervals on capped tenders using a linear distribution $[36,53] .^{1}$

Figure 1 shows that the relationship between bidder position (i) and the probability of surpassing the bidder drops $\left(P_{n t h}\right)$ according to Ballesteros-Pérez et al. (blue line) and follows this expression:

$$
P_{n t h}=\frac{N-i+1}{N}
$$

It must be noted that $\mathrm{i}=1$ corresponds to the lowest bidder (most economical), whereas $\mathrm{i}=\mathrm{N}$ is the highest bidder (most expensive).

Figure1: Diagram showing two possible relationships between i and $P_{\text {nth }}$.

Nevertheless, for detecting abnormal bids it is more suitable to use the following expression in order to reflect a symmetrical continuity correction (not an asymmetrical correction that is more convenient in PPGs). This equation is represented by means of a red line in Figure 1 as well:

$$
P_{n t h}=\frac{N-i+0.5}{N}
$$

It is now necessary to relate a particular bidder's drop $\left(D_{i}\right)$ with a particular level of probability of being surpassed $\left(P_{n t h}\right)$. For the sake of convenience, it would be preferable to use a domain ranging between 0 and 1, instead of ranging between $D_{\text {min }}$ and $D_{\max }$. However, in order to point out an abnormal behavior, no bid should be more distant than $1 /{ }_{N}$ from the bidders' bids extremes, that is, the minimum drop $\left(D_{\min }\right)$ or the maximum drop $\left(D_{\max }\right)$. So, introducing these two corrections enables what the authors have called Standard drops $\left(D_{i}^{\prime}\right)$ to be obtained.

To obtain these Standard drops from a set of bids, firstly, they must be transformed into drops using the expression (1) and then the following expression must be applied:

\footnotetext{
${ }^{1}$ Ballesteros-Pérez et al. (2012c) discuss how bidder position distributions can be better studied by means of beta distributions. However, the usual tender data scarcity regarding the behavior that a particular Economic Scoring Formula generates in the bidders, makes it advisable to use simple linear distributions (which is a particular case of the beta distribution and usually fits well enough).
} 


$$
D_{i}^{\prime}=\frac{1}{2 N}+\frac{N-1}{N} \cdot \frac{D_{i}-D_{\min }}{D_{\max }-D_{\min }}
$$

Then, starting with a series of bids and their respective ordered positions $\left(B_{i}, i\right)$, a new set of points: $\left(D_{i}^{\prime}, P_{n t h}\right)$ is obtained. These last set of points will be properly analyzed below. 


\section{Assumptions}

As Porter and Zona [20, 40] and Bajari and Ye [46, 47] showed in their work, at this point the proposed method must posit the two following assumptions. Firstly, each firm/bidder has private information about its costs. Even though each firm's precise cost is known only to itself, there is public information about factors that affect (although they do not completely determine) various firms' costs. Thus, firms will have some information about the approximate level of their costs relative to those of other firms [54].

Secondly, the method assumes that the bidding strategies by firms are a Bayes-Nash equilibrium. In equilibrium, firms are rational and submit bids that maximize their expected profits, taking into account all possible information about themselves and their rival firms. A profit-maximizing firm must trade off the benefits of increasing its bid (a higher profit conditional on winning) against the costs of increasing its bid (winning the contract with lower probability) [6].

Although other formal and analytical risk models have recently been developed to prescribe how risk is to be incorporated into bids (particularly in construction bids) [55, $56,57,58]$, in practice, price risks are usually excluded from the final bid in order to improve competitiveness [59].

Indeed, some recent conceptual models have also been developed for use by contractors as part of a more reliable approach for identifying key competitors and as a basis for formulating bidding strategies [57, 60]. Competitiveness among bids is examined using linear mixed models that employ variables such as project type and size, work sector, work nature, market conditions, as well as number of bidders $[57,58$, 61]. Some of these variables, such as project type and size, work sector, work nature, and market conditions are very difficult to quantify.

The two assumptions shown at the beginning of this section are a synonym of the following statement: 'if a series of bidders bid with the same criteria, then, their economic bids must follow the same statistical distribution'.

That particular statistical distribution (only applicable when bids have been previously converted into Standard drops) is what the authors call 'Standard Pattern distribution' and whose cumulative distribution equation is:

$$
\mathrm{Y}_{\text {pattern }}=\mathrm{D}_{\mathrm{i}}^{\prime}
$$


That is, the Standard Pattern cumulative distribution represents a bisector line and its values range, according to Equation 4 , from $1 / 2 \mathrm{~N}$ to $1-1 / 2 \mathrm{~N}$ both in the $\mathrm{X}$ and $\mathrm{Y}$ axes. This distribution implies that a group of bidders which has entered a particular tender will be $1 /{ }_{N}$ apart from each other, both in their $D^{\prime}{ }_{i}$ values and $P_{n t h}$ values, whenever they perfectly fit a Standard Pattern distribution.

Nonetheless, a perfect correspondence between the Standard Pattern distribution in a particular tender set of $\left(D_{i}^{\prime}, P_{n t h}\right)$ points is hardly possible; so, in order to establish a zone in which the actual $\left(\mathrm{D}_{\mathrm{i}}{ }, \mathrm{P}_{\mathrm{nth}}\right)$ point distribution can be considered as not far enough from the Standard Pattern line, upper and lower limit lines have been defined. The equations of those limit lines are the following, and they are placed a distance that equals $1 / 2 N$ above and under the Standard Pattern line:

$$
\mathrm{Y}_{\text {lower }}=\mathrm{D}_{\mathrm{i}}^{\prime}-\frac{1}{2 \mathrm{~N}} \quad \mathrm{Y}_{\text {upper }}=\mathrm{D}_{\mathrm{i}}^{\prime}+\frac{1}{2 \mathrm{~N}} \quad \text { (6) and (7) }
$$

Since the line generated by the $\left(D_{i}^{\prime}, P_{n t h}\right)$ points is a multi-segmented curve, it is advisable to begin working with their optimal regression straight line (least squares). In this way, if the optimal straight line is completely inside the zone delimited by the upper and lower limit lines then the bidders' bids distribution can be assumed to be following the principles of conditional independence and exchangeability, that is, no bid or group of (collusive or abnormal) bids has caused a distortion in the group of $\mathrm{N}$ bids greater than an $1 / N$ value.

There is only one exception that must be taken into account. A particular group of bidders could follow two or more Standard Pattern distributions at the same time if they were assuming different ways of carrying out the same tender (for example by using different technologies to perform the same contract). Although this may seem a major drawback, it is not as important as it seems. From among different technologies (if the cause of the difference is due to a different manner of performing the contract, which is the most common cause) the potential contractors or bidders usually know which approach is best (or at least the cheapest), and so they will tend to study their costs with the same assumptions and with few variations. When the contract becomes more complex, regarding the variety and/or necessary steps to be performed, the application of different ways of carrying out each phase tends to lose importance, since most technologies are shared among contractors.

In the case of contracts with a fuzzy scope, this exception might become important, but abnormal bidders should always be able to justify their offers later if they are finally 
considered as abnormal bidders when applying the methodology developed in this paper.

\section{Proposed methodology}

Given a complete set of bidders' bids entered in a tender, the following steps must be fulfilled:

1. Order their values from the least $(i=1)$ to the most expensive $(i=N)$.

2. Calculate the respective drops $\left(D_{i}\right)$ using Equation 1.

3. Calculate the standard drops $\left(D_{i}^{\prime}\right)$ using Equation 4.

4. Calculate the respective probability values $\left(P_{n t h}\right)$ using Equation 3 .

5. Represent the previous new dataset of $\left(D^{\prime}, P_{n t h}\right)$ values in a graph similar to the one shown in Figure 2.

6. Calculate the optimal regression straight line of the $\left(\mathrm{D}_{\mathrm{i}}^{\prime}, \mathrm{P}_{\mathrm{nth}}\right)$ values and draw it in the same graph.

7. Represent the Standard Pattern line (according to Equation 5) and the limit lines (according to Equations 6 and 7 ) in the previous graph.

When this multi-step process is done, a new graph, termed a 'Standard Drop Graph' (SDG) by the authors, will have been generated and a tender analyst will be able to start studying the bidders' bids distribution. An example of a generic SDG is shown in Figure 2.

Figure2: Explanation of the items shown in a Standard Drop Graph (SDG)

As mentioned above, whenever a bidders' bid distribution is close enough to its Standard Pattern line, (i.e., the optimal regression straight line is completely within the zone set by the upper and lower limit lines) the bidders' distribution reflects the 'exchangeability' condition. Nevertheless, a previous condition must also be fulfilled. The quadratic correlation factor of the optimal regression straight line must high enough (usually above 0.90) to say that the bidders' bids dataset is properly represented by this regression curve.

Additionally, the 'conditional independence' condition must be fulfilled. This condition requires another two verifications. Firstly, the residuals generated from the deviations between the $D_{i}$ ' $s P_{n t h}$ and $Y_{\text {standard }}$ values must follow a Normal distribution; thus, a tStudent test must be performed on the residuals dataset. Secondly, the average of the 
$D_{i}^{\prime}$ standard drops ( $\left.D_{m}^{\prime}\right)$ must be close enough to the value 0.5 , that is, not far from the center of the SDG.

Since, a bidders' bids distribution with absence of abnormal and collusive bids is approximately symmetrical around its $D_{m}$ value according to [53], this condition, translated into the new equation stated in the mathematical expression (3), means $D_{m}^{\prime}=P_{n t h}=0.5$. Therefore, a new parameter is created for monitoring the deviation of $D_{m}^{\prime}$,

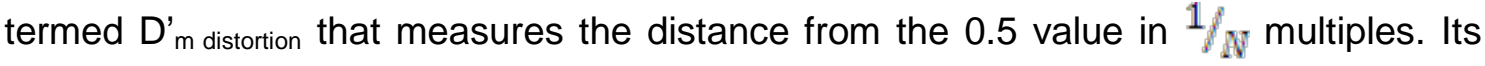
mathematical expression is the following (standard mean drop distortion):

$$
\mathrm{D}_{\mathrm{m} \text { dist. }}^{\prime}=\frac{\frac{\left|\mathrm{D}_{\mathrm{m}}^{\prime}-0.5\right|}{0.5}}{\frac{1}{\mathrm{~N}}}=\mathrm{N} \frac{\left|\mathrm{D}_{\mathrm{m}}^{\prime}-0.5\right|}{0.5}=\mathrm{N}\left|2 \mathrm{D}_{\mathrm{m}}^{\prime}-1\right|=\mathrm{N}\left|2 \frac{\mathrm{D}_{\mathrm{m}}-\mathrm{D}_{\min }}{\mathrm{D}_{\max }-\mathrm{D}_{\min }}-1\right|
$$

Measuring this $D_{m}^{\prime}$ deviation as a function of $1 /{ }_{N}$ multiples reveals how many bidder positions the $\mathrm{D}_{\mathrm{m}}$ value has displaced, since the bidders' positions distance is the same in both the $X$ and $Y$ axes, that is ${ }^{1 / N}$. Usually, a value of $D^{\prime} m$ distortion lower than 1 should be required.

Therefore, in order to ensure 'conditional independence' and 'exchangeability' in a group of bidders, the four mathematical tests explained above should be passed. Whenever a bidding group does not observe one or several of the conditions stated above, it will mean that one or several of the bidders behaved abnormally. If those bidders cannot justify their economic bids, they could be potentially qualified as collusive bidders, especially if they show similar behavior in subsequent tenders.

However, the proposed methodology is only capable of detecting collusive bidders (out of abnormal bids) when the bidders are placed near the $D^{\prime}{ }_{i}$ distribution extremes, that is, they are among the highest or lowest values of the $D_{i}^{\prime}$ dataset. Nonetheless, a collusive bidder generally must be extremely high or low in order to exert sufficient impact on a bidders' distribution, especially when cartel bids are not the majority; so, most commonly, a bidder (or a group of collusive bidders) is forced to be extreme to exert influence and this enables detection.

In order to prove the point above and to close this particular issue, the only four types of common collusive schemes that can be detected by the proposed method are summarized in Table 1.

Table1: Most common bid-covering strategy classification In passive collusive schemes, a protector bid (phony bid or collusive bid) bids extremely low in order to lower the drops average $\left(D_{m}\right)$, so that extremely high non- 
cartel bids are rejected (usually lowering the abnormal threshold specified in the tender specifications). In active collusive schemes, a protector bid takes higher risks and offers extremely high bids in order to raise the drops average $\left(D_{m}\right)$, so that the cartel bid designated as potential bidder is more likely to be inside the abnormality threshold. In both active and passive schemes, the protected bidder (the one who is trying to win and is assisted by supporting or protector phony bids) will choose higher or lower bids depending on the profit margin the particular tender offers the potential contractors.

When the profit margin is low and the protected bidder is among the main body of noncollusive bidders, the protected bidders may be extremely difficult to detect. Nevertheless, in these cases, the protected bidders are not usually acting (in exclusively economic terms) abnormally, since their bids are within the usual profit limits.

\section{Tender review}

To study the Scoring Parameters and Economic Scoring Formulas used in Spain, 120 tender specifications documents from Spanish Public Administrations and private companies were reviewed ([62], Annex I). The review is quite representative of the Spanish tendering system, as it comprises tenders and auctions by both public (city councils, local councils, semi-public entities, universities, ministries, etc.) and private contracting authorities, as well; it includes a wide variety of civil engineering works and services from various geographical regions (including the islands) and features a wide range of economic tender amounts. Although the sample only contains Spanish tender documents, the variables analyzed are directly applicable to any country where requesting administrations or contracting authorities set an initial tender amount against which candidates must underbid (capped tendering or upper-limit-price tendering).

Among the wide range of tender documents collected, several contracting authorities generated sufficient tendering processes to enable an in-depth statistical analysis. Although the results obtained from these contracting authorities were very similar, a sub-dataset from one public administration was selected in order to illustrate (through several numeric examples) the analysis of bidders' bids distribution.

The selected public administration is the 'Agencia Catalana del Agua' (Catalonian Water Agency), ACA hereinafter, a semi-public administration that manages most of the water supply system in the Catalan region of Spain. ACA managed 51 construction tenders in approximately one year (from May 2007 to June 2008) ([62], Annex II).

\section{Calculations and results}


Appendix B reflects the application of the method explained in Section 6 on a subset of three tenders extracted from Ballesteros-Pérez [62] (Annexes I and II). Despite the fact that the authors tried the same test in a large number of different tenders with a wide variety of results regarding the Economic Scoring Formulae, the results are always approximately the same.

In Appendix B, each tender shows two tables: the first table reflects the bidders' bid distribution of that tender taking into account all the bidders. The second table reflects the bidders' bids distribution after removing several bidders' bids that were distorting the distribution sufficiently away from the Standard Pattern distribution (more than $1 /{ }_{N}$ on average). Therefore, the second table in each case reflects those bidders whose bids can be considered as 'normal', while those removed must be initially considered as 'abnormally high or low'. A repeated pattern of abnormality by a particular bidder(s) in several tenders might be considered as potentially collusive, unless the bidder is able to justify (technically and/or economically) why its bids were so unexpectedly high or low on each occasion.

Concerning the structure of the tables shown in Appendix $B$, their organization is as follows. In the top left row, each table contains descriptive data from the tender: code; correspondence with Ballesteros-Pérez [62] Annex II thesis ID; tender deadline; Contracting Public/Private Authority (Cont. Aut.); economic bid weight with regard to the total tender scoring (EBW); and nature of the work (NOW).

Below, also on the left, a second row shows several calculations relative to the tender: number of bidders studied $(\mathrm{N})$; the tender amount (although this is a value that could have been specified in the upper row, it is more convenient to put it here, above the bidders' economic bids); the maximum, minimum, and mean drops $\left(D_{\max }, D_{\min }\right.$ and $D_{m}$, respectively); and the percentage of bidders that have already been removed (Abn. Bids).

Just under the previous row, there is a large table whose columns perform the major calculations stated in the previous sections: the first column is an auxiliary that enables/disables each bidder's data (Active?); the second column reflects the bidder's position (i); the third shows each bid in euros $\left(B_{i}\right)$ which is translated into drops in the fourth column $\left(D_{i}\right)$; the fifth column reflects the Standard drops of each bidder calculated according to Equation $4\left(\mathrm{D}_{\mathrm{i}}^{\prime}\right)$, which are the $\mathrm{X}$-values, while the $\mathrm{Y}$-values correspond to the $P_{n t h}$ values calculated as a function of Equation 3 and represented in column 6; the last but one column shows each bidder's i correspondent $Y_{\text {pattern }}$ value as 
a function of Equation 5; whereas, finally, column eight calculates the differences between $Y_{\text {pattern }}$ and $P_{\text {nth }}$ values, that is, the residuals.

In the top right corner there is a series of three rows in which the main bid distribution acceptance calculations are performed ('monitoring parameters'):

- In the first row, the first two cells are for calculating the mean Standard drop, whose translation into multiples of $1 /{ }_{N}$ are represented in the second cell. Values lower than 1 mean that the bidders' distribution has caused sufficiently little impact. The second cell is calculated according to Equation 8.

- The last cell in the first row evidences the quadratic correlation coefficient of the optimal straight line from the active standard drop bids distribution. This correlation factor coincides with the linear relationship with the Standard Pattern line. It is advisable that this cell exceeds a 0.90 value.

- When the optimal regression line is completely within the zone delimited by the two limit lines calculated by equations 6 and 7, the first cell in the second row reflects the word 'Yes' in blue. This is a necessary condition in order to state that the optimal regression line is close enough to the Standard Pattern distribution. Another two cells in this row represents the optimal regression line's interception and gradient (useful for auxiliary calculations).

- In the third row, a Normality test is performed by means of a t-Student test in the residual dataset. If this test is passed, this will be reflected in the first cell and this means that the bidders' bids distribution oscillates around the Standard Pattern line as a group of bidders with no correlation between them.

To accept a bidders' bid distribution for a particular tender, four conditions must be observed: $D_{m \text { distortion }}<1 ; R^{2}>0.90 ;\left(D_{i}^{\prime}, P_{n t h}\right)$ optimal regression straight line must be completely within zone delimited by the upper and lower limit lines; and their residuals must fit a Normal distribution (checking their t-Student value, with an $\alpha$ value equaling $5 \%$ for instance).

Furthermore, two tables in the right center show accessory calculations to help draw the SDG explained in Section 6. This graph is also represented for each particular selection of bidders in the bottom right corner.

When removing bidders' bids from the initial set of bidders, a tender analyst applying this method must keep in mind the following rule: he/she must always remove the minimum number of bidders in order to fulfill the four 'monitoring parameters'. No matter whether the bidders' bids are from the top or the bottom, whenever their 
removal number is the minimum possible. Concerning which bidders to remove, it is usually advisable to remove the next highest or lowest bidder who makes the $\mathrm{D}_{\mathrm{m}}$ distortion move quicker towards zero, until the remaining bidders fit the Standard Pattern distribution.

To verify the reliability of the method proposed, the authors performed a series of experiments mixing different proportions of 'normal' and 'abnormal' bidders. This led to the conclusion that the model is robust enough whenever two conditions are simultaneously fulfilled:

a) The number of bidders equals or is above five bidders $(\mathrm{N} \geq 5)$.

b) The number of collusive bids (including the protected bidder) is below $50 \%$ of the total number of bidders.

Initially, sensitivity analysis proved that whenever there are three or four bidders, the method would be mathematically consistent, but in the case of collusion with so few total bidders, collusive bidders would represent a percentage of bidders equal to or above $50 \%$ (since at least one protector bidder plus the protected bidder would total two collusive bidders), and hence, the collusion phenomenon would be undetectable.

\section{Discussion and conclusions}

So far, no empirical techniques for detecting collusion are likely to be flawless and complete by themselves. Nonetheless, the authors believe that the approach described in this paper is a useful further step since it resolves several problems identified with earlier models:

- Until now, models have only been applied to auctions, not to tenders, in which other non-economic criteria are implemented.

- Models usually require plenty of information about the potential bidders and the project details in order to apply the statistical tests for checking the two conditions (conditional independence and exchangeability). Therefore, previous tests have only been applied to relatively simple tenders.

- Previous models require advanced mathematical regression techniques and a sufficient number of previous tenders to be applicable.

- A sufficiently sophisticated cartel could avoid detection using tests for conditional independence and exchangeability in order to remain undetected. Porter and Zona [20] documented that the residuals to estimate bid functions for firms in the cartel are much more highly correlated with each other than the 
residuals for the non-cartel firms. However, if a cartel plans to mimic competitive behavior then this can be achieved.

The method presented here partly solves these problems because:

- It can be applied to general tenders, both public and private, just as the tenders used as examples in this paper to illustrate the method implementation.

- No information is needed about the potential bidders (except for their economic bids) or about the project, since only abnormally high and/or low bids are detected.

- The required mathematical calculations are very simple and the particular representation of the bidders' bids guides the auctioneer or Contracting Authority at any time regarding deviations from a Standard Pattern distribution.

- This method cannot be used the other way around, i.e., it cannot be applied by a cartel to disguise a series of phony bids, except when the cartel's firms are a majority of the total number of bidders.

Nonetheless, the proposed method has two main limitations:

1. It is only useful for detecting abnormally high or low bids, while discovering whether those bids are collusive or not would require a repetitive pattern in several tenders by the same companies and further investigation to be performed by the Contracting Authority. This problem is shared with previous methods.

2. It does not provide information about potential collusive behavior located in the middle of the bidders' bids range, i.e., only highest and lowest bids stand out concerning this method.

These two limitations are constrained by the fact that in order to generate a sufficient effect on the bid distribution almost any fraudulently covering bid must be extremely high or low, since the closer a collusive bid is to the bids' average $\left(D_{m}\right.$ when expressed in drops), the less collusive its effect is.

Furthermore, it must be pointed out that the test presented in this paper can be complemented with existing tests, enabling an auctioneer to minimize the disadvantages of each test.

Concerning the robustness of the model, sensitivity analysis to all monitoring parameters proved its reliability when the number of bidders equals five or more and the number of collusive bids (including the protected bidder) does not equal or surpass 
half of the total number of bidders. Therefore, when preparing tender specifications, the auctioneer or Contracting Authority should bear in mind that open tendering processes with publicity always attract a larger number of bidders (increasing this method's reliability) but, if it were necessary to resort to a selective tendering process, the number of invited bidders should always exceed four.

\section{Future work}

From a research viewpoint, the method presented in this paper has only been applied to capped tendering. Nevertheless, the different variables the method uses can be transformed to be set as a function of monetary values instead of drop values, which is indispensable on uncapped tendering. The next aim is to research the Standard Pattern line that bidders' bids distribution follows on uncapped tenders.

Whereas capped tendering can use drops (X-axis values ranging from 0 to 1 ), uncapped tendering will have to use semi-infinite ranges of values on the $X$-axis (prices ranging from 0 to infinite). Moreover, both capped and non-capped tendering share some statistical conditions, so the adaption can be researched.

In parallel with this test adaptation to uncapped tenders, a comprehensive study on how to alert to the possibility of collusive bidders that are near the average of the bids distribution will be continued.

However, from a practical viewpoint, that is, with regard to operatively implementing this new tool in the public and private sector, the authors recommend initially introducing this method as a sort of background test (only for the eyes of the Contracting Authority), so they will be able to know which potential collusive activity is taking place in its tenders without any previous knowledge about it from the bidders.

If the method eventually proved to be a new useful ALBC for a particular Contracting Authority's context, then it would be up to the person in charge of supervising the tenders to decide whether this method should be integrated within future tender specifications or remain as a concealed monitoring tool. 


\section{Appendix A}

Main abbreviations used in the text:

A Amount of money of a tender (upper price limit)

ACA Agencia Catalana del Agua (owner of tendering sub-dataset analyzed)

ALBC Abnormally low bids criteria

$B_{i} \quad$ Bidder's $i$ bid (expressed in monetary value)

BTFM Bid tender forecasting model

$D_{i} \quad$ Bidder's i drop (expressed in per-unit value)

$D_{m} \quad$ Mean drop (expressed in per-unit value)

$D_{\max } \quad$ Maximum drop (expressed in per-unit value)

$D_{\min } \quad$ Minimum drop (expressed in per-unit value)

$D_{\text {nth }} \quad$ Bidder's nth drop (expressed in per-unit value)

ESF Economic scoring formula

i Bidder's i position

$\mathrm{N} \quad$ Total number of bidders for a particular tender

$\mathrm{P}_{\mathrm{nth}} \quad$ Probability of surpassing bidder nth (usually expressed in per-unit value)

PPG Position probability graph

SDG Standard drop graph

SW Sewage system

WWTP Waste water treatment plant

\section{Appendix B}

Three examples of bidders' bids distribution analysis.

Table 2: Analysis of bidders' bids distribution (Tender \#1) with all bidders

Table 3: Analysis of bidders' bids distribution (Tender \#1) with extreme bidders eliminated

Table 4: Analysis of bidders' bids distribution (Tender \#2) with all bidders 
Table 5: Analysis of bidders' bids distribution (Tender \#2) with extreme bidders eliminated

Table 6: Analysis of bidders' bids distribution (Tender \#3) with all bidders

Table 7: Analysis of bidders' bids distribution (Tender \#3) with extreme bidders eliminated

\section{Acknowledgements}

The translation of this paper was funded by the Universitat Politècnica de València.

\section{References}

[1] OECD Observer (Organisation for Economic Co-operation and Development). Guidelines for fighting bid rigging in public procurement. April 2009, p. 5(1).

[2] OECD (Organisation for Economic Co-operation and Development). Bribery in Procurement, Methods, Actors and Counter-Measures, (2007) ISBN 978-92-64-013940

[3] Aoyagi, M. and Fréchette, G., Collusion as public monitoring becomes noisy: Experimental evidence. Journal of Economic Theory, 144(3) (2009),1135-1165.

[4] Marshall, R. C. and Marx, L. M., The vulnerability of auctions to bidder collusion.(Report). Quarterly Journal of Economics, 124(2) (2009), 883-910.

[5] Bajari, P. and Summers, G., Detecting collusion in procurement auctions. Antitrust Law Journal, 70(1) (2002), 143-170.

[6] Hendricks, K., Porter, R. and Tan, G., Bidding rings and the winner's curse. The RAND Journal of Economics, 39(4) (2008), 1018-1041.

[7] Ishii, R., Collusion in Repeated Procurement Auction: A Study of a Paving Market in Japan. Osaka University, Institute of Social and Economic Research, ISER Discussion Paper 0710 (2008).

[8] Blume, A. and Heidhues, P., Modeling tacit collusion in auctions. Journal of Institutional and Theoretical Economics, 164(1) (2008), 163-184.

[9] Hu, A., Offerman, T. and Sander, O., Fighting collusion in auctions: An experimental investigation. International Journal of Industrial Organization, 29(1) (2011), 84-96. 
[10] Klemperer, P., What really matters in auction design. Journal of Economic Perspectives, 16 (2002), 169-190.

[11] Anderson, L., Freeborn, B. and Hulbert, J., Risk aversion and tacit collusion in a Bertrand Duopoly experiment. Review of Industrial Organization, 40(1) (2012), 37-50.

[12] Che, Y.-K. and Kim, J., Robustly collusion-proof implementation. Econometrica, 74 (2006), 1063-1107.

[13] Che, Y.-K. and Kim, J., Optimal collusion-proof auctions. Journal of Economic Theory, 144 (2008), 565-603.

[14] Chowdhury, P. R., Controlling collusion in auctions: The role of ceilings and reserve prices. Economics Letters, 98(3) (2008), 240-246.

[15] Graham, D.M., and Marshall, R.C., Collusive bidder behavior at single-object second-price and English auctions. Journal of Political Economy, 95 (1987), 12171239.

[16] Jeon, D.S. and Menicucci, D., Optimal second-degree price discrimination and arbitrage: On the role of asymmetric information among buyers. RAND Journal of Economics, 36 (2005),337-360.

[17] Laffont, J. and Martimort, D., Collusion under asymmetric information. Econometrica, 65 (1997), 875-911.

[18] Laffont, J. and Martimort, D., Mechanism design with collusion and correlation. Econometrica, 68 (2000), 309-342.

[19] Ishii, R., Favor exchange in collusion: Empirical study of repeated procurement auctions in Japan. International Journal of Industrial Organization, 27(2) (2009), 137144.

[20] Porter, R. H. and Zona, J. D., Detecting of bid rigging in procurement auctions. Journal of Political Economy, 101(3) (1993), 518-538.

[21] Porter, R. H., Detecting collusion. Review of Industrial Organization, 26 (2005), 147-167.

[22] Rasch, A. and Wambach, A., Internal decision-making rules and collusion. Journal of Economic Behavior \& Organization, 72 (2009), 703-715. 
[23] Gayle, W.R. and Richard, J., Numerical solutions of asymmetric, first-price, independent private values auctions. Computational Economics, 32(3) (2008), 245278.

[24] Engelbrecht-Wiggans, R., State of the art - auctions and bidding models: a survey. Management Science, 26(2) (1980), 119-142.

[25] Fayek, A., Competitive bidding strategy model and software system for bid preparation. Journal of Construction Engineering and Management, 124 (1998), 1-10.

[26] Harstad, R.M. and SašaPekec, A., Relevance to practice and auction theory: a memorial essay for Michael Rothkopf. Interfaces, 38(5) (2008), 367-380.

[27] Näykki, P., On optimal bidding strategies. Management Science, 23(2) (1976), 198-203.

[28] Rothkopf, M.H. and Harstad, R.M., Modeling competitive bidding: a critical essay. Management Science, 40(3) (1994), 364-384.

[29] Skitmore, R.M., The contract bidder homogeneity assumption: an empirical analysis. Construction Management and Economics, 9(5) (1991), 403-429.

[30] Skitmore, R.M., The probability of tendering the lowest bid in sealed auctions: an empirical analysis of construction data. Journal of the Operational Research Society, 53(1) (2002), 47-56.

[31] Skitmore, R.M., Predicting the probability of winning sealed bid auctions: the effects of outliers on bidding models. Construction Management and Economics, 22(1) (2004), 101-109.

[32] Skitmore, R.M., First and second price independent values sealed bid procurement auctions: some scalar equilibrium results. Construction Management and Economics, 26(8) (2008), 787-803.

[33] Watt, D.J., Kayis, B. and Willey, K., Identifying key factors in the evaluation of tenders for projects and services. International Journal of Project Management, 27(3) (2009), 250-260.

[34] Ballesteros-Pérez, P., González-Cruz, Ma.C., Pastor-Ferrando, J.P. and Fernández-Diego, M., The iso-Score Curve Graph. A new tool for competitive bidding. Automation in Construction, 22 (2012), 481-490. 
[35] Ballesteros-Pérez, P., González-Cruz, Ma.C. and Cañavate-Grimal, A., Mathematical relationships between scoring parameters in capped tendering. International Journal of Project Management, 30 (2012), 850-862.

[36] Ballesteros-Pérez, P., González-Cruz, $M^{a}$.C. and Cañavate-Grimal, A., On Competitive Bidding: Scoring and Position Probability Graphs. International Journal of Project Management. (2012) DOI: 10.1016/j.jproman.2012.09.012

[37] Baldwin, L., Marshall, R. and Richard, J. F., Bidder collusion at Forest Service Timber Sales. Journal of Political Economy, 105(4) (1997), 657-699.

[38] Maskin, E. and Riley, J., Asymmetric auctions. The Review of Economics Studies, 67(3) (2000), 413-438.

[39] Pesendorfer, M., A study of collusion in first-price auctions. Review of Economic Studies, 67(3) (2000), 381-411.

[40] Porter, R. H. and Zona, J. D., Ohio School Milk Markets: an analysis of bidding. Rand Journal of Economics, 30(2) (1999), 263-288.

[41] McAfee, R. P. and McMillan, J., Bidding rings. American Economic Review, 82(3) (1992), 579-599.

[42] Aoyagi, M., Bid rotation and collusion in repeated auctions. Journal of Economic Theory, 112 (2003), 79-105.

[43] Skrzypacz, A. and Hopenhayn, H., Tacit collusion in repeated auctions. Journal of Economic Theory, 114(1) (2004), 153-169.

[44] Harrington, J. E., Detecting Cartels. Economics Working Paper Archive, Johns Hopkins University (2005).

[45] Paha, J., Empirical methods in the analysis of collusion. Empirica, 38(3) (2011), 389-415.

[46] Bajari, P. and Ye, L., Competition Versus Collusion in Procurement Auctions: Identification and Testing. Stanford University Working Paper (2001).

[47] Bajari, P. and Ye, L., Deciding between competition and collusion. Review of Economics and Statistics, 85(4) (2003), 971-989. 
[48] Chao, L. and Liou, C., Risk-minimizing approach to bid-cutting limit determination. Construction Management and Economics, 25(8) (2007), 835-843.

[49] Skitmore, R.M., Graphical method for identifying high outliers in construction contract auctions. Journal of the Operational Research Society, 52 (2001), 800-809.

[50] Skitmore, R.M. and Lo, H.P., A method for identifying high outliers in construction contract auctions. Engineering, Construction and Architectural Management, 9(2) (2002), 90-130.

[51] Carr, P.G., Investigation of bid price competition measured through pre bid project estimates, actual bid prices and Number of bidders. Journal of Construction Engineering and Management, 131(11) (2005), 1165-1172.

[52] Ngai, S.C., Drew, D.S., Lo, H.P. and Skitmore, R.M., A theoretical framework for determining the minimum number of bidders in construction bidding competitions. Construction Management and Economics, 20(6) (2002), 473-482.

[53] Runeson, G., An analysis of the accuracy of estimating and the distribution of tenders. Construction Management and Economics, 6 (1988), 357-370.

[54] Makadok, R., The interaction effect of rivalry restraint and competitive advantage on profit: why the whole is less than the sum of the parts. Management Science, 56(2) (2010), 356-372.

[55] Hartono, B. and Yap, C.M., Understanding risky bidding: a prospect-contingent perspective. Construction Management and Economics, 29(6) (2011), 579-593.

[56] Mohamed, K.A., Khoury, S.S. and Hafez, S.M., Contractor's decision for bid profit reduction within opportunistic bidding behavior of claims recovery. International Journal of Project Management, 29(1) (2011), 93-107.

[57] Oo, B.L., Drew, D.S. and Lo, H.P., A comparison of contractors' decision to bid behaviour according to different market environments. International Journal of Project Management, 26(4) (2008), 439-447.

[58] Oo, B.L., Drew, D.S. and Lo, H.P., Heterogeneous approach to modeling contractors' decision-to-bid strategies. Journal of Construction Engineering and Management, 134(10) (2008), 766-776. 
[59] Laryea, S. and Hughes, W., Risk and price in the bidding process of contractors. Journal of Construction Engineering and Management, 137(4) (2011), 248-259.

[60] Oo, B., Drew, D.S. and Runeson, G., Competitor analysis in construction bidding. Construction Management and Economics, 28(12) (2010), 1321-1329.

[61] Drew, D.S. and Skitmore, R.M., The effect of contract type and size on competitiveness in bidding. Construction Management and Economics, 15 (1997), 469489.

[62] Ballesteros-Pérez, P., Doctoral Thesis: "Propuesta de un nuevo modelo para la predicción de bajas en licitaciones de Construcción". González Cruz, MC. dir.; Pastor Ferrando, JP. dir.. (2010). Universal Identifier: http://hdl.handle.net/10251/7025 